stronger, its first dissociation constant being a thousand times as great as that of the other compound. The apparent inability of the enolised $\alpha$-hydroxy- $\beta$-ketonic ester type of compound to account for the acid properties of $l$-ascorbic acid suggests that some other grouping is responsible for its large first dissociation constant. It may, however, be suggested that the use of the ordinary hydrogen electrode with a compound containing a double bond requires further investigation.

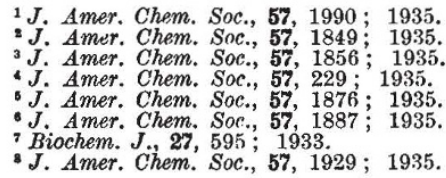

\title{
Fire Resistance of Buildings
}

A LABORATORY of an unusual kind was opened by H.R.H. the Duke of Kent at the end of last month. This is the Fire Testing Station erected at Elstree by the Fire Offices Committee, an organisation representing the tariff insurance companies, for the purpose of investigating the resistance to fire of building materials and elements of structure.

The need of such an institution has been apparent for some years, and has been steadily growing. Little enough is known of the protection against fire afforded by the traditional types of building material, and still less of the many new types which have appeared in recent years. This uncertainty is reflected in the building codes issued by local authorities, which, so far as provisions against fire are concerned, are often contradictory.

A good deal of research has been carried out abroad, notably at the Underwriters Laboratory at Chicago; and in Great Britain, before and during the Great War, the now defunct British Fire Prevention Com. mittee investigated certain aspects of the problem. But the first attempt in Great Britain to put the whole subject on a sound basis was taken by the British Standards Institution in 1932. In this year, it published "Definitions for the Fire Resistance, Incombustibility and Non-Inflammability of Building Materials and Structures" (B.S.S. No. 476), which laid down a test procedure for assessing the fire resistance of structural elements by means of a standard test upon full-sized specimens.

From the evidence of actual fires and from demonstration tests, it has been established that the tem. perature within a fiercely burning building rises rapidly to about $1,500^{\circ} \mathrm{F}$. and thereafter more slowly up to a maximum of about $2,007^{\circ} \mathrm{F}$. The standard test provides that specimens shall be heated in accordance with a time-temperature curve which approximates to that of recorded conflagrations; furnace temperatures of $1,000^{\circ} \mathrm{F} ., 1,700^{\circ} \mathrm{F}$. and $2,300^{\circ} \mathrm{F}$. are required at the expiration of 5 minutes, 1 hour and 8 hours respectively from the beginning of the test. It is also necessary to take account of the effect of water from fire hoses impinging on a heated structure. The specification therefore requires that immediately following the period of heating the specimen shall be subjected to a jet from a fire hose applied under standardised conditions for a period equal to one minute for each hour of fire exposure. In the case of load-bearing structures, it is further provided that a load equal to $1 \frac{1}{2}$ times the working load shall be maintained on the specimen throughout the whole period of the test. In certain cases, the load must be re-applied forty-eight hours after the completion of firing.
According to the period which elapses between the beginning of the test and the failure of the specimen, the specimen is classified into one of five grades, the highest being represented by a fire-resistance period of six hours and the lowest by one of half an hour.

In the case of walls, floors and other elements which function as separating structures, the specimen is heated on one side only, and failure is indicated either by a temperature rise on the unexposed face of more than $250^{\circ} \mathrm{F}$., or by the development of cracks through which flame can pass, or by collapse under load. Columns and other elements which serve only as load bearers are heated on all sides and are said to have failed when collapse under load occurs.

By issuing this specification, the British Standards Institution not only provided a clear basis for the study of the subject, but also directed attention to the absence of adequate testing facilities. As a result of a conference between interested bodies, the Fire Offices Committee undertook to provide these facilities and the Department of Scientific and Industrial Research to assist in the solution of technical problems.

The Testing Station at Elstree consists of two buildings : one contains equipment for testing the fire-resistance of structural elements; in the other, provision is made for continuing the work on sprinklers, fire-extinguishers and other appliances which has hitherto been carried out by the Committee at Manchester. For testing structural elements, three units have been provided-for walls, columns and floors respectively. In each case, heat is provided by a gas-burning furnace operated electrically from a control room adjoining and overlooking the main building. The gas-air mixture is fed to the burners through 'inspirators' which automatically maintain a constant proportion of the two ingredients at all pressures ; the air is supplied at a maximum pressure of approximately 15 in. of water and the gas at the normal pressure of the mains. The fuel supplied to different parts of the furnace is controlled separately, with the view of maintaining a uniform temperature over the whole area of the specimen.

Both furnace and specimen temperatures are recorded by thermocouples connected to instruments located in the control room. Platinum rhodium platinum couples are used for furnace temperatures, and chromel-alumel or copper-constantan couples for specimen temperatures. The leads from each separate equipment pass through a bus-board mounted on the instrument panel, by means of which a quick change-over may be effected from one furnace to another. 
In the wall and column units, the load is applied to the specimen by mounting it in a heavy, built-up steel frame designed so that an upward thrust can be given to the bottom beam of the frame by means of hydraulic rams. The rams are operated on a maximum oil pressure of two tons per square inch, the oil being supplied by an electric pump and the load being recorded by a pendulum dynamometer in the control room. These loading frames have a maximum capacity of 500 tons. They stand in pits in the floor of the building, and the furnaces used in conjunction with them are built on wheels so that they can be moved away for the water test. In the floor testing unit, the furnace is fixed and the specimen is lifted away for the water test by a 30-ton travelling electric crane.

The essential aim of the Station is to provide the means of carrying out tests, as rapidly and economic- ally as possible, on the basis of the standard specification. A considerable amount of work upon tradi. tional materials is required, but tests of new types will be run concurrently.

Arrangements have been made whereby the facilities of the Station will be available to the Department of Scientific and Industrial Research, through its Building Research Station, both for carrying out a general programme of research into the fire resistance of traditional materials, and for conducting tests on behalf of manufacturers in accordance with a fixed schedule of charges, when a certificate of performance is required. It is hoped that the industry will take full advantage of the opportunity which now occurs to have the fireresisting properties of its products assessed on a proper basis.

\section{Scientific Research in Transport}

\section{New Laboratory of the London, Midland and Scottish Railway}

$\mathrm{L}^{\mathrm{O}}$ ORD RUTHERFORD opened the new research laboratory at Derby of the L.M.S. Railway on December 10 (see Nature, December 14, p. 949). A distinguished party of guests travelled from St. Pancras by special train, the engine of which was named "Lord Rutherford of Nelson" by Lord Rutherford's small grandson, Pat Fowler, and at Derby luncheon was served on the train. Speeches made during luncheon by Sir Josiah Stamp and Lord Rutherford were relayed to the various cars, and everyone heard excellently. In his speech, the former specially welcomed Sir William Bragg and Sir James Jeans. $\mathrm{He}$ recalled that when he was president of the Institute of Transport, he devoted his presidential address to the subject of scientific research in transport and expressed his gratification that some of his dreams have now come true. The days of haphazard and rule of thumb tests are over; the days of controlled and directed experiment under arranged conditions have fully arrived. At the same time, he said, "I would like to stress the fact that we are not trying in this new laboratory to supersede or to rival scientific effort in all directions". The company is still extending its use of outside facilities in connexion with the Department of Scientific and Industrial Research.

Lord Rutherford, in declaring the new laboratory open, said that the L.M.S. is described as a public utility company; but it is more like a State within a State, as it has a gross revenue of nearly seventy millions and its own sea, land and air forces all organised for the most efficient service to the community. On the map, the railway appears to be not merely the backbone but rather the whole vertebrate system of Great Britain. Lord Rutherford said he is convinced that there is scarcely a single unit, whether of machinery or lay-out or even of organisation, that cannot be improved for its purpose by the application of scientific research. But even when valuable results are obtained, there still remains the serious difficulty of introducing them into this great organisation, which has developed over long years a successful routine. To obtain the best results from a laboratory such as the one at Derby, it is essential to develop mutual respect and understanding between the scientific man and the practical man. He expressed. the hope that the officers and staff of the Railway will take the greatest interest in the new laboratory and utilise its services to help solve their problems.

Lord Rutherford then declared the laboratory open, and the staff and visitors were divided into groups and shown over it, some of them also inspecting the wagon and locomotive works.

The L.M.S. Railway is probably the largest com. mercial undertaking in the world. It has an authorised capital of 439 million pounds and gives employment to 223,000 persons. In addition to 7,000 miles of line open to traffic, it possesses 8,000 locomotives, hundreds of thousands of vehicles, 45 steamers and 31 hotels. In addition, it conducts several extensive manufacturing undertakings in connexion with its transport business. In 1930, Sir Harold Hartley was appointed vice-president and director of scientific research. In 1932, the chemical, paint, metallurgical and textile laboratories were formed into a research department. The effect of the completion of the new laboratory is to concentrate in one building the various research sections. In addition to possessing a large staff of specialists to deal with the various problems which are continually arising, the depart. ment utilises to the fullest extent the research organisation of the Department of Scientific and Industrial Research. It is also a member of six research associations, and allocates certain problems to research laboratories at the universities.

The Metallurgical Section is concerned with investigations relating to the selection of metals and their manipulation by casting, forging, heat treatment and welding. It also examines materials which have failed to give a satisfactory performance in service. The Engineering Section deals with research on the design and performance of engineering details of machines and structures. It studies aerodynamical problems connected with the air resistance of trains, with wind pressures, ventilation systems and so on. The Textile Section is responsible for the inspection and testing of the various textile materials purchased by the Company, and for drawing up specifications 